\title{
Mental Health Problems among Korean American Adolescents
}

\author{
Minjeong Kim¹, Jyu-Lin Chen ${ }^{2}$, Susan Kools ${ }^{3}$, Sandra Weiss ${ }^{4}$ \\ ${ }^{1}$ School of Nursing, San Diego State University, San Diego, USA \\ ${ }^{2}$ Department of Family Health Care Nursing, University of California, San Francisco, USA \\ ${ }^{3}$ Department of Family, Community and Mental Health Systems, University of Virginia, Charlottesville, USA \\ ${ }^{4}$ Department of Community Health Systems, University of California, San Francisco, USA \\ Email: minjeong.kim2@gmail.com
}

How to cite this paper: Kim, M., Chen, J.-L., Kools, S., \& Weiss, S. (2016). Mental Health Problems among Korean American Adolescents. Psychology, 7, 1872-1882. http://dx.doi.org/10.4236/psych.2016.714172

Received: September 30, 2016

Accepted: December 4, 2016

Published: December 7, 2016

Copyright $\odot 2016$ by authors and Scientific Research Publishing Inc. This work is licensed under the Creative Commons Attribution International License (CC BY 4.0).

http://creativecommons.org/licenses/by/4.0/ (c) (i) Open Access

\begin{abstract}
Korean American adolescents are a population that may be particularly vulnerable to mental health problems because of the potential cultural conflicts they face during an important developmental period. Yet little is known about the prevalence of their mental health problems. The aims of this study were to determine the prevalence of various mental health problems in a sample of Korean American adolescents, and to identify whether gender or age of the youth are associated with the types or severity of their mental health problems. This cross-sectional study included 138 Korean American adolescents from community settings in California. A demographic questionnaire and the Youth Self Report (YSR) were completed by adolescents. Descriptive analyses and t-tests were used to examine the aims. Percent of the sample falling into "normal", "borderline", and "clinical" ranges for different mental health problems was also determined based on normative scores provided in the YSR manual. Results indicate that $18 \%$ of the Korean American adolescents experienced clinically significant mental health problems. Most problems were of the internalizing type such as anxiety and depression where almost $23 \%$ of the youth reached the cutoff for clinical significance. The youth also experienced high levels of social problems, thought problems, and attention problems. However, scores for somatic complaints, rulebreaking behavior, and aggressive behavior as well as the composite score for externalizing problems were in the "normal" range. Girls reported higher levels of anxiety/depression and somatic complaints than boys, contributing to their higher internalizing score as well. Boys and older adolescents reported higher levels of rulebreaking behavior. A substantial percent of Korean American adolescents in this sample reported symptoms of anxiety and depression, especially girls. Findings suggest the need to screen for these problems in pediatric care and for development of prevention and referral programs in Korean American communities.
\end{abstract}




\section{Keywords}

Mental Health, Adolescents, Asian Americans

\section{Introduction}

Koreans are the fifth largest Asian American subgroup following the Chinese, Filipino/a, Indian, and Vietnamese (Rhee, Chang, \& Rhee, 2003). The Korean community has a recent trend of immigration history in the United States (Choi, 2008; Yeh, 2003). Although the Korean American population is rapidly increasing, little is known about the mental health problems of Korean American adolescents (Lai, 2005; Lim, Stormshak, \& Falkenstein, 2011; Takeuchi, Hong, Gile, \& Alegría, 2007).

Adolescence is recognized as a challenging time for all adolescents but it may put Korean American adolescents at particular risk for mental health problems. Approximately, $80 \%$ of these youth have parents who have immigrated to the US or who have themselves immigrated to the US as children (Kim, Cain, \& McCubbin, 2006; Passel, 2011). Immigration stressors such as cultural differences, discrimination, and changes in social support or income have been associated with mental health problems for these families (Bernstein, Park, Shin, Cho, \& Park, 2011; Choi, Miller, \& Wilbur, 2009). In spite of these factors, very few studies have examined mental health problems of Korean American adolescents.

Cho and Bae (2005) examined internalizing behavior problems (i.e. depression, anxiety, withdrawal, and somatic problems) of 340 Korean American adolescents in a metropolitan area. In their study, adolescents reported a mean of $16.4(S D=9.9)$ out of 62 points for internalizing behavior problems, indicating they had more mental health problems than the norm when compared to typical adolescents who had not been referred for psychiatric care (Achenbach \& Rescorla, 2001). In another metropolitan sample of 217 Korean American youth, Shrake and Rhee (2004) found that the adolescents reported a moderate level of both internalizing and externalizing (i.e. aggression, rule-breaking) behavior problems. Yeh (2003) examined mental health symptoms in 141 Chinese, 122 Korean, and 54 Japanese American adolescents. Korean American adolescents reported a mean of $1.28(S D=0.65)$ out of 5 points on the Symptom CheckList-90-Revised (SCL-90-R), which was higher than Chinese $(M=0.90)$ and Japanese $(M=0.99)$ adolescents, but still low.

Two studies focused specifically on depressive symptoms in Korean American adolescents. Shin, D’Antonio, Son, Kim, \& Park (2011), in an investigation of the relationship between bullying experience and depressive symptoms of 295 Korean American adolescents, found that those who experienced being bullied and those who experienced both being bullied and bullying reported levels of depression above the clinical cut-off score of 16 ( $M=18.0$ - 19.3). Kim and Cain (2008), in their study of parenting and depressive symptoms of 56 Korean American adolescents, found that about $40 \%$ of the participants had clinically meaningful depressive symptoms. 
Gender and age differences have been examined in a few studies. Findings regarding gender differences in mental health problems of Korean American adolescents are inconsistent. Shrake and Rhee (2004) found that females had more internalizing behavior problems than males, whereas other studies found no gender differences in mental health problems (Cho \& Bae, 2005; Kim \& Cain, 2008). Lee, Yim, Curry, \& Rodriguez (2012) reported that females had less school delinquency than males, whereas other studies found no gender differences in delinquency (Lee et al., 2012) or in externalizing behavior problems (Shrake \& Rhee, 2004). With the exception of one study, no age differences in mental health problems have been reported. Lee et al. (2012) found that older adolescents had more serious delinquency and school delinquency, whereas other studies found no age differences in any mental health problems (Cho \& Bae, 2005; Kim \& Cain, 2008; Lee et al., 2012).

The purpose of this study was to advance existing knowledge by clarifying the types of mental health problems that may most frequently occur in Korean American youth and the potential differences in specific problems by gender and age. Research to date indicates that Korean American adolescents have minimal to moderate levels of mental health problems but little is actually known about the specific types of mental health problems experienced by these youths and whether some problems are more prevalent than others. Almost nothing is known about the prevalence of social, thought, and attention problems because they are not considered either internalizing or externalizing problems. Lastly, there are conflicting findings regarding the degree to which gender and age may play a role in severity of these problems. The specific aims of this study were 1) to determine the prevalence of various mental health problems in a sample of Korean American adolescents, and 2) to identify whether gender or age of the youth are associated with the types or severity of their mental health problems.

\section{Methods}

\subsection{Participants and Setting}

The sample included 138 Korean American adolescents: 1) 10 - 19 years old, 2) is able to communicate in English or in Korean, 3) self-identified as Korean American, and 4) is able to understand the purpose of the study. Through convenience sampling, participants were recruited from Korean churches and language schools, community mental health centers serving Asian Americans and Pacific Islanders, Korean shopping malls and restaurants, and websites for the Korean community in California.

\subsection{Procedure}

The study was approved by the Committee on Human Research (CHR) of the University of California, San Francisco. If an adolescent was interested in participating, a packet of materials (including self-report measures and an informed written consent for both the adolescent and the parent) was sent. Participants returned completed materials to the researcher. Follow-up phone calls, mail, or e-mail occurred when necessary to gather additional information. The recruitment period was from January 2013 
through December 2014.

\subsection{Measures}

\subsubsection{Demographic Questionnaires}

A 6-item investigator developed demographic questionnaire was used. The items consisted of age, gender, parents' educational level, adequacy of family income, and length of residence in the US.

\subsubsection{Youth Self Report}

The Youth Self Report (YSR) was used to measure mental health problems of the participants. It is a self-report questionnaire for youth $11-18$ years of age to assess their problematic feelings, thoughts, and behaviors during the past 6 months (Achenbach \& Rescorla, 2001). The YSR contains 112 items with 3-point Likert scale. The higher score means the greater psychological distress. The YSR has eight empirically-based syndrome scales: Anxious/Depressed, Withdrawn/Depressed, Somatic Complaints, Social Problems, Thought Problems, Attention Problems, Rule-Breaking Behavior, and Aggressive Behavior. These are then calculated into composite scores for Internalizing Problems, Externalizing Problems, and Total Problems. Cut-offs for normal, clinical and borderline concern were also determined based on established scores in the YSR manual. The clinical range is derived from research that has established scores for adolescents who are being treated for mental health problems in a clinical setting. The Borderline range reflects scores that are close to the clinical range but do not quite meet the cut-off. Scores in the normal range reflect samples of children who have not been referred for mental health problems. All comparison scores are gender-specific.

Varied studies have shown good to excellent Cronbach's alpha scores for the eight empirically-based syndrome scales $(\alpha=0.67-0.86)$, Internalizing Problems $(\alpha=0.89$ $0.90)$, Externalizing Problems $(\alpha=0.89-0.90)$, and Total Problems scales $(\alpha=0.93$ 0.95) (Achenbach \& Rescorla, 2001; Ebesutani, Bernstein, Martinez, Chorpita, \& Weisz, 2011; Ivanova et al., 2007; Rescorla et al., 2007). Validity and factor structure of the YSR have also been established (Achenbach \& Rescorla, 2001; Ebesutani et al., 2011; van Lang, Ferdinand, Oldehinkel, Ormel, \& Verhulst, 2005). The YSR has been translated into about 40 languages and used in about 40 countries including Korea as well as in Western countries (Ivanova et al., 2007; Rescorla et al., 2007). Therefore, the YSR is considered to be a reliable and valid instrument for measuring the mental health problems of Korean American adolescents.

\subsection{Data Analysis}

Descriptive statistics were used to examine sample characteristics, including frequency and percent for gender, parents' educational level, and adequacy of family income, and means and standard deviations ( $S D S$ ) for age and length of residence in the US. In order to examine the prevalence of various mental health problems in the sample (Aim 1), means and $S D s$ were calculated for eight empirically-based syndrome scales, which were then used to create mean scores for the composite scales: Internalizing Problems, 
Externalizing Problems, and Total Problems. Percent of the sample falling into "normal", "borderline", and "clinical" ranges was determined for all scores based on $T$ scores provided in the YSR manual. After assessing normality of distribution for the mental health problem scales, log transformations were conducted for Thought Problems and Rule-Breaking Behavior because these two scores were skewed. Lastly, to examine differences in gender and age (Aim 2), t-tests were conducted to compare the mean level of the eight empirically-based syndrome scales as well as Internalizing Problems, Externalizing Problems, and Total Problems. For the age comparison, youth were divided into 2 groups of 15 and older or 14 and younger based on the mean age of the participants of this study. The level of significance for all statistical tests was set at 0.05. Data were analyzed using SPSS version 22 .

\section{Results}

Participants consisted of 57 males (41.3\%) and 81 females (58.7\%). The mean age of the participants was 14.43 years ( $10-19$ years, $S D=2.09$ ). About $67 \%$ of the participants were born in the US. About $87 \%$ of fathers and $80 \%$ of mothers had a college or higher education. About $61 \%$ of the participants reported that "their family had enough money but no extra" and 36\% reported that "they had more money than they need" (see Table 1).

Table 1. Demographic characteristics of Korean American adolescents $(N=138)$.

\begin{tabular}{|c|c|}
\hline Variable & $n(\%) / M(S D)$ \\
\hline \multicolumn{2}{|l|}{ Gender } \\
\hline Male & $57(41.3)$ \\
\hline Female & $81(58.7)$ \\
\hline Age & $14.43(2.09)$ \\
\hline \multicolumn{2}{|l|}{ Birthplace } \\
\hline U.S. & $93(67.4)$ \\
\hline Korea or other & $45(32.6)$ \\
\hline \multicolumn{2}{|l|}{ Father's Education } \\
\hline High school or below & $17(12.8)$ \\
\hline College or vocational school & $22(16.5)$ \\
\hline Associate or Bachelor degree & $47(35.3)$ \\
\hline Graduate school of higher & $47(35.3)$ \\
\hline \multicolumn{2}{|l|}{ Mother's Education } \\
\hline High school or below & $26(19.7)$ \\
\hline College or vocational school & $19(14.4)$ \\
\hline Associate or Bachelor degree & $48(36.4)$ \\
\hline Graduate school of higher & $39(29.5)$ \\
\hline \multicolumn{2}{|l|}{ Family Income } \\
\hline Not enough money for food and place to live & $0(0.0)$ \\
\hline Not enough money for clothes or school supplies & $4(3.0)$ \\
\hline Enough money but no extra & $82(60.7)$ \\
\hline More money than we need & $49(36.3)$ \\
\hline
\end{tabular}


Participants' type and severity of mental health problems are presented in the Table 2. Among eight empirically-based syndrome scales, the $T$ score mean on the anxious/depressed scale was the highest $(M=58.6, S D 8.6)$, followed by means on social problems $(M=57.9, S D 7.1)$ and withdrawn/depressed $(M=57.5, S D 8.1)$. The $T$ score mean of rule-breaking behavior was the lowest $(M=53.6, S D 4.7)$. For internalizing problems (including the anxious/depressed, withdrawn/depressed, and somatic complaints scales), the $T$ score mean was $55.4(S D=10.7)$. For externalizing problems (including the rule-breaking behavior and aggressive behavior scales), the $T$ score mean of $51.2(S D=9.3)$ was reported. The $T$ score mean for total problems (including social, thought, attention, and other problems scales as well as internalizing and externalizing problems) was 54.1 ( $S D=10.1)$. As shown in Table 2 , about $20 \%$ of the participants fell into either the borderline and clinical ranges for anxious/depressed, withdrawn/depressed, and social problems, whereas only $2 \%$ of the participants fell into the borderline or clinical ranges for rule-breaking behavior. $22.6 \%$ of the participants were in the clinical range for internalizing problems, $8.1 \%$ for externalizing problems, and about $17.6 \%$ for total problems. Those reaching a level of borderline concern included $16.1 \%$ of the youth for internalizing problems, $11.8 \%$ for externalizing problems, and $11.5 \%$ for total problems.

Mean $T$-scores for gender and age are also shown in Table 2. Independent sample t-tests indicated significant gender differences in the level of anxious/depressed $(t(136)$ $=-3.10, p<0.01)$, somatic complaints $(t=-2.68$ (135), $p<0.01)$, and rule-breaking behavior scales $(t=2.55$ (134), $p<0.05)$. Girls had higher mean scores for being anxious/depressed (7.96 vs. 5.42) and for somatic complaints (3.83 vs. 2.55), while boys had higher scores for rule-breaking behavior (4.04 vs. 2.86). Among the 3 overarching, combined scales, girls had a significantly higher level of internalizing problems than boys (16.27 vs. $11.98, t=-2.81$ (132.4), $p<0.01)$. On the remaining scales, boys and girls demonstrated comparable scores for their mental health problems. For age, there was one significant difference; it was for rule-breaking behavior $(t=-2.68(134), p<$ 0.01). Adolescents 15 years old or older reported significantly higher levels of rulebreaking behavior than adolescents 14 or younger (3.90 vs. 2.78). There were no other significant age group differences.

\section{Discussion}

Findings indicate that approximately $18 \%$ of Korean American adolescents in this sample from the western United States experienced clinically significant mental health problems. Most of these problems appeared to be of the internalizing type where scores for almost $23 \%$ of the youth were in the clinical range; that is, their scores were comparable to youth who are being treated for mental health problems in clinical settings. Anxiety/depression was the primary mental health problem of these youth, with $20 \%$ falling into either the clinical or borderline ranges. $19 \%$ were in the clinical or borderline ranges for withdrawal/depression. The youth also experienced high levels of social problems, with almost $19 \%$ in the clinical or borderline ranges. In each of these areas, Korean American adolescents in this study had more mental health problems than the 
Table 2. Tscore means and percent of mental health problems in the normal, borderline, and clinical ranges by gender and age.

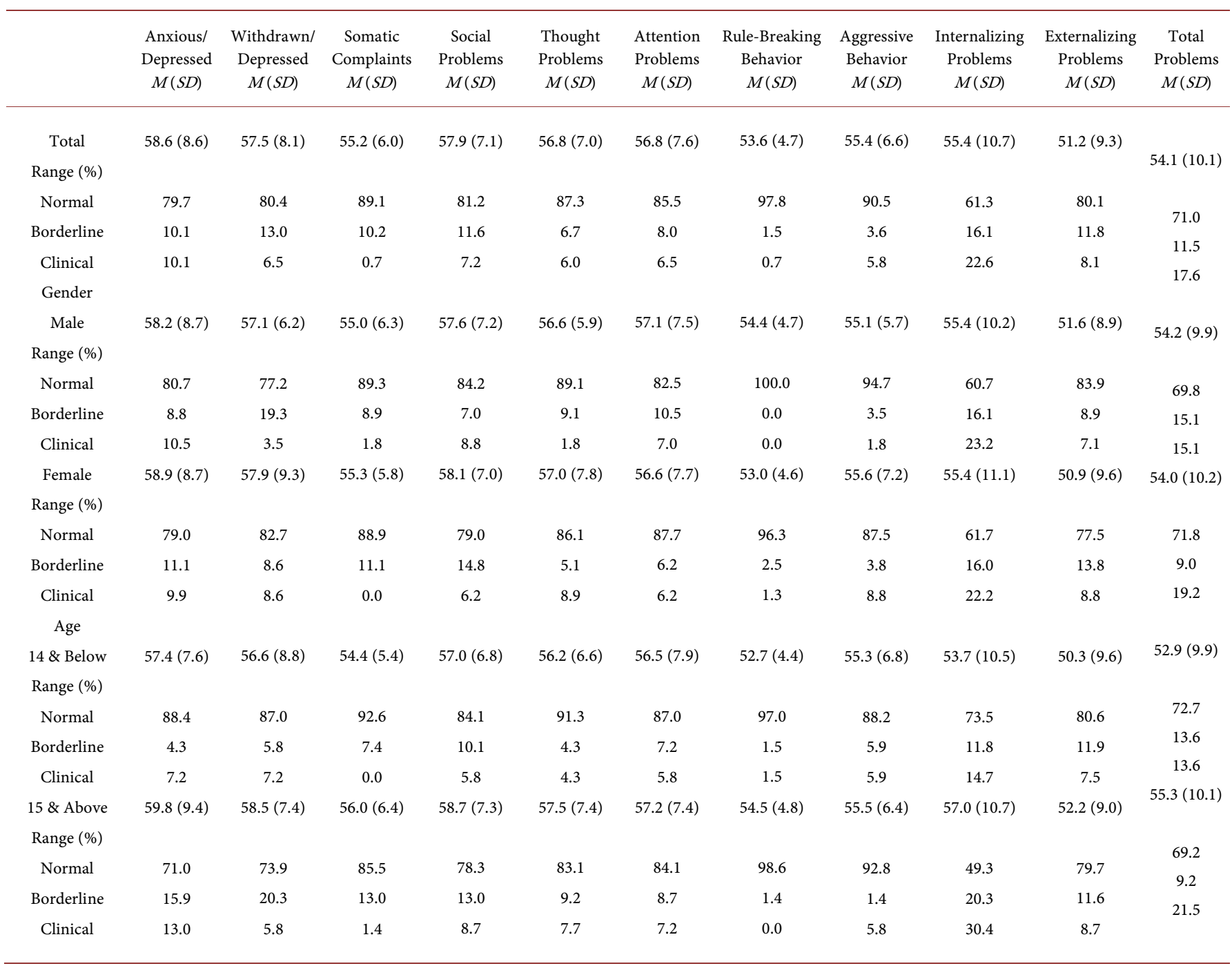

Note. Gender n's were 57 male and 81 female; 69 youth were 14 and younger, 69 youth were 15 and older.

norm when compared to typical adolescents who had not been referred for psychiatric care (Achenbach \& Rescorla, 2001). Their scores for thought problems and attention problems were also slightly higher than established norms. However, scores for somatic complaints, rule-breaking behavior, and aggressive behavior as well as the composite score for externalizing problems were comparable to the norms identified for nonreferred children in the US.

Compared to previous studies of Korean American youth, scores for anxious/depressed, withdrawn/depressed, somatic complaints, and internalizing problems in our study were comparable or slightly lower than what Cho and Bae (2005) found. The difference may be due to different characteristics of the samples in these two studies. Participants of our study were 0.6 years younger than those of Cho and Bae's (2005) study. Because older age has been significantly associated with more mental health problems, the younger population in this study might show fewer mental health problems. Al- 
though it is difficult to compare scores from our study with those of Shrake and Rhee's (2004) research due to a difference in score calculations, Korean American adolescents in both studies experienced fewer externalizing problems than internalizing problems. Congruent with our results, Shrake and Rhee found that Korean American adolescents had high levels of anxiety/depression and social problems and low levels of rulebreaking behavior. These findings are also consistent with previous results of ethnic group comparisons, indicating that Asian American adolescents had more anxiety disorders and social problems but less delinquent behavior than European American adolescents, although some Asian American subgroup differences were found (Lorenzo, Frost, \& Reinherz, 2000; Nguyen et al., 2004; Willgerodt \& Thompson, 2006; Yeh, 2003).

Considering our results in conjunction with that of previous research, it would appear that anxiety, depression and social challenges are a major concern for a substantial percent of Korean American youth. These problems could stem to some extent from the dual expectations faced by these adolescents as they attempt to accommodate values of both their traditional Korean culture and those of the US during a time of developmental transition. Traditional Confucian values such as interdependence, interpersonal harmony, conformity to family and social norms, and strong respect for elders (Greenfield, Keller, Fuligni, \& Maynard, 2003; Kim, Atkinson, \& Umemoto, 2001) may be in conflict with the values and behavior of their US peers. US adolescents may be more likely to challenge authority, place less emphasis on alignment with family norms, and strive for independence than Korean American adolescents. It has been proposed that this conflict in values may lead to difficulty adjusting and increased risk for internalizing problems (Rhee et al., 2003).

Our findings that Korean American adolescents had slightly higher attention and thought problems than the norm are some of the first to be reported. Results of the one previous study that examined attention problems among Asian American adolescents did not find higher levels than the norm (Nguyen et al., 2004). So our findings need replication. Although our results could suggest a risk for attention-deficit disorder, findings could also indicate a high level of concern among the youth regarding their school performance. This interpretation is based upon the questions about school performance and trouble concentrating that are part of the attention scale and the very high expectations to excel in education within Korean American families. To our knowledge, there has been no other study with Asian American adolescents that has examined thought problems of Korean American youth. Although the YSR "thought problems scale" has been linked to a number of psychiatric symptoms and disorders, its relationship to obsessive-compulsive behavior (OCB) may be relevant here (Hudziak et al., 2006; Ivarsson, Melin, \& Wallin, 2007). Our findings could reflect a greater emphasis among Korean American adolescents than other adolescents on certain behaviors that are similar to OCB (e.g. perfectionism and being overly conscientious) since these are valued qualities among Korean Americans (Kim et al., 2001).

A number of gender differences emerged in the findings. Girls reported significantly 
higher levels of anxiety/depression and somatic complaints, contributing to their higher internalizing score as well. In contrast, boys had more rule-breaking behavior than girls. These results are consistent with findings from most previous research with Korean American adolescents (Cho \& Bae, 2005; Lee et al., 2012; Shrake \& Rhee, 2004) and with adolescents in general (Rockville, 2009, 2011). However, the findings are in conflict with one study of Korean American adolescents that found no gender differences in depressive symptoms (Kim \& Cain, 2008). As to age differences in mental health problems, older adolescents reported significantly higher levels of rule-breaking behavior. This finding is consistent with results from a previous study of Korean American adolescents that found a positive correlation between age and delinquent problems (Lee et al., 2012) and with research of adolescents in general (Rockville, 2009, 2011). However, the findings are in conflict with one study that found no age differences in externalizing problems between younger (13 - 15 years old) and older Korean American adolescents (16 - 18 years old) (Shrake \& Rhee, 2004).

Limitations of the study should be noted. Because participants were recruited in California, the findings may not be generalized to Korean Americans throughout the US. In addition, $70 \%$ of the sample were second or higher generation immigrants whose parents were well-educated. Findings may be different for adolescents who have immigrated more recently or are from lower socioeconomic backgrounds. However, our sample characteristics are consistent with those in other studies of Korean Americans (Cho \& Bae, 2005; Passel, 2011). In addition, the convenience sample may have not included a broad or representative distribution of mental health problems. Lastly, self-report measures of mental health were used; it is possible that clinician evaluation or inclusion of parent report would have provided a more comprehensive assessment of participants' mental health problems.

Further research is needed using a multi-method approach to assessing mental health with more representative samples of youth. In addition, it is important to identify factors that may contribute to the high prevalence of depression, anxiety and social problems for Korean American adolescents. Studies to further examine the prevalence of attention and thought problems are also needed, including assessments to clarify whether the youth are at risk for particular psychiatric disorders such as ADHD or Obsessive Compulsive Disorder.

Despite study limitations, our findings contribute to a more comprehensive understanding of Korean American adolescents' mental health problems. Results have particular implications for assessment. Pediatric and adolescent clinicians need to screen for depression and anxiety as part of their ongoing care. Symptoms of these problems may not manifest overtly, especially among Korean American youth who have been socialized as part of their culture to show positive emotions in their interactions with others. Prevention programs also need to be developed in Korean American communities, including awareness among families of symptoms associated with depression and anxiety as well as resources for referral of youth who may need more comprehensive assessment and treatment. 


\section{References}

Achenbach, T. M., \& Rescorla, L. A. (2001). Manual for the ASEBA School-Age Forms and Profiles. Burlington, VT: University of Vermont Research Center for Children, Youth, \& Families.

Bernstein, K. S., Park, S. Y., Shin, J., Cho, S., \& Park, Y. (2011). Acculturation, Discrimination and Depressive Symptoms among Korean Immigrants in New York City. Community Mental Health Journal, 47, 24-34. https://doi.org/10.1007/s10597-009-9261-0

Cho, S., \& Bae, S.-W. (2005). Demography, Psychosocial Factors, and Emotional Problems of Korean American Adolescents. Adolescence, 40, 533-550.

Choi, J., Miller, A., \& Wilbur, J. (2009). Acculturation and Depressive Symptoms in Korean Immigrant Women. Journal of Immigrant and Minority Health, 11, 13-19. https://doi.org/10.1007/s10903-007-9080-8

Choi, Y. (2008). Diversity within: Subgroup Differences of Youth Problem Behaviors among Asian Pacific Islander American Adolescents. Journal of Community Psychology, 36, 352-370. https://doi.org/10.1002/jcop.20196

Ebesutani, C., Bernstein, A., Martinez, J. I., Chorpita, B. F., \& Weisz, J. R. (2011). The Youth Self Report: Applicability and Validity across Younger and Older Youths. Journal of Clinical Child and Adolescent Psychology, 40, 338-346. https://doi.org/10.1080/15374416.2011.546041

Greenfield, P. M., Keller, H., Fuligni, A., \& Maynard, A. (2003). Cultural Pathways through Universal Development. Annual Review of Psychology, 54, 461-490.

https://doi.org/10.1146/annurev.psych.54.101601.145221

Hudziak, J. J., Althoff, R. R., Stanger, C., van Beijsterveldt, C. E., Nelson, E. C., Hanna, G. L., \& Todd, R. D. (2006). The Obsessive Compulsive Scale of the Child Behavior Checklist Predicts Obsessive-Compulsive Disorder: A Receiver Operating Characteristic Curve Analysis. Journal of Child Psychology and Psychiatry, 47, 160-166.

https://doi.org/10.1111/j.1469-7610.2005.01465.x

Ivanova, M. Y., Achenbach, T. M., Dumenci, L., Rescorla, L. A., Almqvist, F., Weintraub, S., \& Verhulst, F. C. (2007). Testing the 8-Syndrome Structure of the Child Behavior Checklist in 30 Societies. Journal of Clinical Child and Adolescent Psychology, 36, 405-417. https://doi.org/10.1080/15374410701444363

Ivarsson, T., Melin, K., \& Wallin, L. (2007). Categorical and Dimensional Aspects of Co-Morbidity in Obsessive-Compulsive Disorder (OCD). European Child \& Adolescent Psychiatry, 17, 20-31. https://doi.org/10.1007/s00787-007-0626-Z

Kim, B. S. K., Atkinson, D. R., \& Umemoto, D. (2001). Asian Cultural Values and the Counseling Process: Current Knowledge and Directions for Future Research. Counseling Psychologist, 29, 570-603. https://doi.org/10.1177/0011000001294006

Kim, E., \& Cain, K. C. (2008). Korean American Adolescent Depression and Parenting. Journal of Child and Adolescent Psychiatric Nursing, 21, 105-115. https://doi.org/10.1111/j.1744-6171.2008.00137.x

Kim, E., Cain, K., \& McCubbin, M. (2006). Maternal and Paternal Parenting, Acculturation, and Young Adolescents' Psychological Adjustment in Korean American Families. Journal of Child and Adolescent Psychiatric Nursing, 19, 112-129. https://doi.org/10.1111/j.1744-6171.2006.00059.x

Lai, M. H. (2005). Responding to Asian Pacific Islander Youth Violence: Lessons Learned from a Community Mobilization Strategy. Crime \& Delinquency, 51, 158-179.

https://doi.org/10.1177/0011128704273467

Lee, G., Yim, K., Curry, T., \& Rodriguez, S. F. (2012). The Relevance of Social and Cultural Con- 
texts: Religiosity, Acculturation and Delinquency among Korean Catholic Adolescents in Southern California. The Social Science Journal, 49, 537-544.

https://doi.org/10.1016/j.soscij.2012.06.001

Lim, M., Stormshak, E. A., \& Falkenstein, C. A. (2011). Psychosocial Adjustment and Substance Use of Cambodian and Vietnamese Immigrant Youth. Journal of Cross-Cultural Psychology, 42, 104-119. https://doi.org/10.1177/0022022110362747

Lorenzo, M. K., Frost, A. K., \& Reinherz, H. Z. (2000). Social and Emotional Functioning of Older Asian American Adolescents. Child \& Adolescent Social Work Journal, 17, 289-304. https://doi.org/10.1023/A:1007598007205

Nguyen, L., Arganza, G. F., Huang, L. N., Liao, Q., Nguyen, H. T., \& Santiago, R. (2004). Psychiatric Diagnoses and Clinical Characteristics of Asian American Youth in Children's Services. Journal of Child and Family Studies, 13, 483-495. https://doi.org/10.1023/B:JCFS.0000044729.93879.c2

Passel, J. S. (2011). Immigrant Children. Demography of Immigrant Youth: Past, Present, and Future. The Future of Children, 21, 19-42. https://doi.org/10.1353/foc.2011.0001

Rescorla, L. A., Achenbach, T. M., Ivanova, M. Y., Dumenci, L., Almqvist, F., Bilenberg, N., Verhulst, F. et al. (2007). Behavioral and Emotional Problems Reported by Parents of Children Ages 6 to 16 in 31 Societies. Journal of Emotional and Behavioral Disorders, 15, 130-142. https://doi.org/10.1177/10634266070150030101

Rhee, S., Chang, J., \& Rhee, J. (2003). Acculturation, Communication Patterns, and Self-Esteem among Asian and Caucasian American Adolescents. Adolescence, 38, 749-768.

Rockville (2009). The National Survey on Drug Use and Health (NSDUH) Report: Major Depressive Episode and Treatment among Adolescents.

Rockville (2011). The National Survey on Drug Use and Health (NSDUH) Report: Substance Use among Asian Adolescents.

Shin, J. Y., D’Antonio, E., Son, H., Kim, S.-A., \& Park, Y. (2011). Bullying and Discrimination Experiences among Korean-American Adolescents. Journal of Adolescence, 34, 873-883. https://doi.org/10.1016/j.adolescence.2011.01.004

Shrake, E. K., \& Rhee, S. (2004). Ethnic Identity as a Predictor of Problem Behaviors among Korean American Adolescents. Adolescence, 39, 601-622.

Takeuchi, D. T., Hong, S., Gile, K., \& Alegría, M. (2007). Developmental Contexts and Mental Disorders among Asian Americans. Research in Human Development, 4, 49-69. https://doi.org/10.1080/15427600701480998

Van Lang, N. D. J., Ferdinand, R. F., Oldehinkel, A. J., Ormel, J., \& Verhulst, F. C. (2005). Concurrent Validity of the DSM-IV Scales Affective Problems and Anxiety Problems of the Youth Self-Report. Behaviour Research and Therapy, 43, 1485-1494. https://doi.org/10.1016/j.brat.2004.11.005

Willgerodt, M. A., \& Thompson, E. A. (2006). Ethnic and Generational Influences on Emotional Distress and Risk Behaviors among Chinese and Filipino American Adolescents. Research in Nursing \& Health, 29, 311-324. https://doi.org/10.1002/nur.20146

Yeh, C. J. (2003). Age, Acculturation, Cultural Adjustment, and Mental Health Symptoms of Chinese, Korean, and Japanese Immigrant Youths. Cultural Diversity and Ethnic Minority Psychology, 9, 34-48. https://doi.org/10.1037/1099-9809.9.1.34 
Submit or recommend next manuscript to SCIRP and we will provide best service for you:

Accepting pre-submission inquiries through Email, Facebook, LinkedIn, Twitter, etc. A wide selection of journals (inclusive of 9 subjects, more than 200 journals)

Providing 24-hour high-quality service

User-friendly online submission system

Fair and swift peer-review system

Efficient typesetting and proofreading procedure

Display of the result of downloads and visits, as well as the number of cited articles

Maximum dissemination of your research work

Submit your manuscript at: http://papersubmission.scirp.org/

Or contact psych@scirp.org 